\title{
Capacity building as a strategic tool for employment equity implementation in the financial sector
}

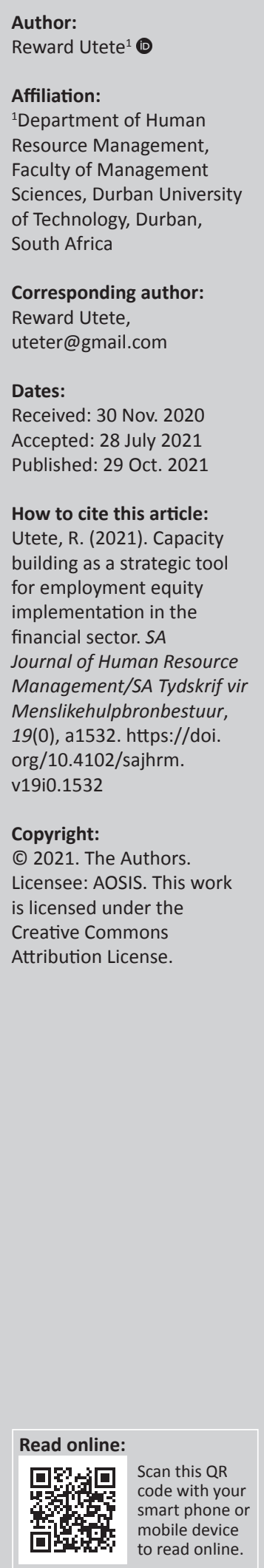

Orientation: Employment equity (EE) has gradually seeped into various levels of many organisations, from private to public companies and small to large companies, in both developing and developed countries.

Research purpose: The aim of this study was to investigate the influence of capacity building on EE implementation with particular reference to the financial sector.

Motivation for the study: The rise in demand for EE appointees and the lack of skills and reasonable accommodation of these employees in the workplace hamper EE implementation in South Africa. For this reason, a pool of employees from the designated groups remains stuck at the unskilled and semi-skilled skills levels.

Research approach or design and method: This study utilised the exploratory research approach. In addition, the study adopted a quantitative research methodology. A sample size of 172 was considered appropriate for this study and returned usable responses were $n=95$.

Main findings: The key findings revealed that capacity building is imperative in promoting the implementation of EE in the workplace. Based on the findings of this study, it is undeniable that improved capacity building is a strong catalyst for executing EE.

Practical or managerial implications: The findings of this study serve as a guide for decision-making and provide advice related to capacity building and implementation of EE to both business leaders and line management.

Contribution or value-addition: The current study contributes new insights and builds the knowledge base on how capacity building influences EE implementation.

Keywords: capacity building; employment equity; designated groups; South Africa; financial sector.

\section{Introduction}

\section{Orientation}

Racial discrimination and the consistent poverty experienced by people from previously disadvantaged groups have forced national governments to enact conventions at global level and statutes at country level that govern stakeholders and actors in the labour market. Of note are the conventions of the International Labour Organisations, the United Nations as well as the African Union's Agenda 2063 which seek to accomplish gender parity by 2030 (Horwitz \& Jain 2011). The South African Constitution, in Section 9(3) and 4, dictates the prohibition of discrimination against any person by any other person. The Employment Equity Act (EEA) focuses on affirmative action and the removal of unfair discrimination measures in the workplace in a bid to align with the requirements of the United Nations (UN), International Labour Organization (ILO), Africa Union and the Constitution of South Africa.

In the context of South Africa, Sesant (2017) highlights that although the Economically Active Population (EAP) of the African group is $77.4 \%$, its representation is predominantly under the category of unskilled employees accounting for $83.2 \%$ and $76.3 \%$ of the semi-skilled category. Furthermore, although the EAP of the black people (African, Indian and Coloureds) constitutes $90 \%$ of the total EAP, in the financial sector, the senior managerial level only consists of $48 \%$ black people across the entire spectrum of financial organisations, whilst only $30 \%$ of black people occupy the top managerial level and $64 \%$ at the middle management level (Department of Economic Development and Tourism 2014). A remarkable number of employees from the designated groups are unable to be promoted given that these jobs demand higher competencies. Consequently, the pool of the employees in the designated group remains stuck at unskilled and semi-skilled skills 
levels. The term designated groups refer to black people (African, Indian and Coloureds), white women and people with disabilities who were previously discriminated against and denied opportunities by the apartheid regime.

The literature reviewed reveals that there is no evidence that any study has examined the influence of capacity building on employment equity (EE) implementation. In the context of this study, capacity building refers to the development of skills, operational infrastructure, and processes as well as the micro-environment of the organisation in order to achieve organisational goals (Maiyo \& Yamoah 2013). Although various studies were conducted on each individual variable, none of those studies researched incorporating either two of the variables or all three variables. Recent studies related to this current study are the following: (1) a study carried out by Olckers and Zyl (2016) on the relationship between EE perceptions and psychological ownership in a South African mining house using a quantitative methodology; (2) a study carried out by Jain, Horwitz and Wilkin (2012) on EE in Canada and South Africa: A comparative review using a systematic review methodology and (3) a study carried out by Horwitz and Jain (2011) on an assessment of EE and Broad Based black Economic Empowerment developments in South Africa methodology. This research sought to fill the gap that exists within these studies.

\section{Problem statement}

Poor accommodation of designated employees in the workplace as well as their lack of skills and experience is retarding EE implementation in financial sector companies. Canham (2012) states that EE appointees have insufficient competences and are, therefore, mainly appointed for window dressing and for in filling quotas. A skills audit carried out by Statistics South Africa (2017) shows that the margin of black African technical, professional and managerial employees in the age group of 25-35 years had slumped by $2 \%$ over 20 years. Potgieter, Coetzee and Ximba (2017) also point out that the conversion of the business environment into a disability-friendly environment is often neglected by organisations in South Africa. Equally, the lack of necessary equipment to support people with disabilities tends to hinder their effectiveness and efficiency in bringing tangible results to their appointed positions. Given an estimate that $1.2 \%$ of people with disabilities are employed, one tends to find that approximately $0.8 \%$ of them fall under the semi-skilled work category. The other significant constituency of designated employees, namely women, makes up a large percentage of the population in South Africa but accounts for approximately only one-third of the workforce (Commission-for-Employment-Equity, 2020). Although the organisation under this study in its 2017 Integrated Annual Report states that it does not have any appetite for non-compliance, it has a great underrepresentation of women and people with disabilities across all races at the managerial levels of the company. The organisation's 2018 Integrated Annual Report indicates that although women comprise $64 \%$ at the workplace, they only constitute $33 \%$ of the management (middle management and above). A remarkable number of employees from the designated groups are unable to be promoted given that the managerial jobs demand high competencies.

Therefore, this study sought to fill the existing research gap by determining the following research objectives.

\section{Main objective}

- Establish the impact of capacity building on EE implementation.

\section{Sub-objectives}

- Establish the extent to which the provision of professional development impacts EE implementation.

- Determine the extent to which organisational processes influence EE implementation.

- Establish the extent to which the state of the internal environment impacts the EE implementation.

\section{Literature review The concept of capacity building}

Capacity building has many interpretations and meanings which vary according to the context within which it is utilised in and who utilises it. Capacity building is closely related to human resources development. In the context of this study, capacity building refers to the development of skills, operational infrastructure and processes as well as the micro-environment of the organisation in order to achieve organisational goals (Maiyo \& Yamoah, 2013). According to El-Mouallem and Analoui (2014), the term 'capacity' does not mean the same thing as 'capacity building'. In fact, the lack of 'capacity' triggers the emergence of the term 'capacity building'. Therefore, for proper capacity building to take place, it should be preceded by an appropriate assessment of the current capacity. Capacity building strengthens the organisation and its facilities, and also concentrates on conditions that permit employees to engage in the transformation process and change adaptation. Capacity building could be categorised as building decisionmaking capacity, building awareness capacity, and building analytical capacity. However, capacity building is viewed as an endogenous dynamic which greatly depends on an individual's perseverance, effort and motivation to progress and learn. In other words, without meaningful perseverance, effort and motivation on the part of the learner, capacity building does not achieve its intended purpose.

The facets of professional development include mentoring, learnerships, coaching, apprenticeship, workshops, understudy, team-building, job rotation and simulations, amongst others. The facets of organisational policy encompass the streamlining of processes, procedures and systems, promotion policy, training policy, career pathing, succession planning, job re-design, mission and vision, amongst others. In order to fully 
grasp the concept of capacity building, the framework provided by Maiyo and Yamoah (2013) has been utilised to conceptualise capacity building (see Table 1).

In reference to this particular research study, the facets of the environment relate to internal environmental aspects. Shams (2016) states that the company is expected to develop the internal environment of the organisation to make it conducive for employees from designated groups, particularly employees with disabilities. Ojokuku and Adegbite (2014) see professional development as a long-term process of enhancing non-human and human potential. Whilst all employees have to live up to the job demands as well as performing at their level best, similar expectations are held for employees from designated groups. Ahmad, Farrukh and Nazir (2015) state that the facets of organisational policy and process development encompass the streamlining of processes, procedures and systems, career paths, succession planning, job re-design, mission and vision, amongst others. Farah and Waqar (2015) state that the internal aspects of the environment include physical aspects such as the level of comfort (natural lighting, artificial lighting, overall comfort), office layout (work area) and non-physical aspects such as organisational structure, company culture, mission and objectives, amongst others.

\section{Implementation and critical evaluation of the importance of employment equity}

The purpose of the EEA is to achieve equity in the workplace by promoting equal opportunity and fair treatment in employment (Matyala 2016). This is done by the elimination of unfair discrimination and implementing affirmative action measures in order to redress the disadvantages in employment experienced by designated groups and to bring about their equitable representation in all occupational categories and levels in the workforce. In terms of fair treatment, the EEA protects two groups of employees under designated groups: (1) employees from designated employees who are already employed within the organisation and (2) persons from designated groups who are applying for jobs against unjust discrimination (Mkhonza 2017). The economic division or gap between the have-nots and the haves is shortened by the EE's entrenchment of the elimination of discrimination and hence builds a sustainable and solid base for development in South Africa. However, the EE puts emphasis on numerical representations of designated employees at different levels in the organisation whilst

TABLE 1: Approaches to capacity-building and their methods.

\begin{tabular}{ll}
\hline $\begin{array}{l}\text { Key approaches to capacity } \\
\text { building }\end{array}$ & Methods of approaches to capacity building \\
\hline $\begin{array}{l}\text { Professional development } \\
\text { or skills development }\end{array}$ & $\begin{array}{l}\text { Learnerships, coaching, workshops, mentoring, } \\
\text { apprenticeships, team-building, job rotations, } \\
\text { secondments and stretch assignments, } \\
\text { understudying, simulations }\end{array}$ \\
$\begin{array}{l}\text { Organisational policy and } \\
\text { process development }\end{array}$ & $\begin{array}{l}\text { Streamlining of processes, procedures and systems, } \\
\text { benchmarking, career pathing, succession planning, } \\
\text { mission and vision. In this study, organisational } \\
\text { processes relate to the promotion and training policies. }\end{array}$ \\
Internal environment & $\begin{array}{l}\text { Physical environment. In this study, the internal } \\
\text { environment relates to the support, culture, physical } \\
\text { appearance and general reporting relationships } \\
\text { within the organisation. }\end{array}$ \\
\hline
\end{tabular}

Source: Adapted from Maiyo, P., \& Yamoah, E.E. (2013). Capacity building and employee performance. Journal of Canadian Social Science, 9(3), 42-45. overlooking the fact that they need to be skilled to suitably fit into positions. Heerden (2015) indicates that although setting numeric goals is important, the government should note that the achievement of successful EE implementation demands more than the mere aspect of getting the numbers right.

\section{Theoretical model: Kolb's experiential learning theory}

Mostly, intelligence of higher value is linked to skills and competencies that are acquired through experience. Because of its emphasis on experience, this research study adopts Kolb's Experiential Learning Theory. According to Yeo and Marquardt (2015), Kolb's Experiential Learning Theory explains the process of learning through experience. It reflects knowledge formation as a result of experiential transformation. Knowledge is acquired through the comprehension of experiential aspects. The Experiential Learning Theory further states that the acquisition of knowledge takes place in a cyclical manner. In this regard, effective learning takes place when one completes the entire cycle. Li, Mobley and Kelly (2013) state that the experiential learning model has four learning stages in which the two polar opposites indicate dimensions of grasping experience, namely abstract conceptualisation and concrete experience whilst another two opposite polar dimensions show transforming experience, namely active experimentation and reflective observation. As such, experiential learning is a knowledge construction process that incorporates deliberate creative tension amongst these four learning dimensions.

\section{Critical evaluation of the connection between capacity building and employment equity implementation}

Many organisations tend to neglect engaging in comprehensive capacity building, thereby hampering efficiency, growth, effectiveness and productivity. According to Yülek (2018), capacity building improves an employee's capability to effectively deal with disequilibria in the labour market. In this case, the disequilibrium is addressed by reviewing the human resource development policies and embarking on the re-allocation of organisational resources as part of dealing with the internal environment. An acute lack of capacity to properly meet the responsibilities of certain higher level positions by employees from designated groups does affect the inclusivity of these individuals in financial organisations. Horwitz and Jain (2011) state that a change process that recognises EE requires all employees from designated groups to develop novel skills so that they deliver up to the standard of their appointed duties. Only if capacity building is adequately adopted to harness professional development, it will help employees acquire the necessary skills expected of them in their positions.

A study conducted by Felício, Couto and Caiado (2014) on human capital, social capital and organisational performance found that high professional experience of managers offers exceptionally strong support when facing work challenges. According to Jenna (2015), organisations that continuously capacitate their employees with skills and resources always 
have willing and ready employees from designated groups to succeed in up to $61 \%$ of positions that may arise within the organisation. Businesses need to properly perform the jobs they get paid to do. Therefore, enforcing black people quotas when it is obvious that the job can neither get done nor meet the minimum standards because of inadequate experience is meaningless.

The rise in demand of EE appointees and the lack of skills and reasonable accommodation amongst these employees hamper EE implementation at the workplace. A study carried out by Portnoi (2003) focused on EEA in South Africa's higher education sector using a systematic review method and found that the dearth of qualified and skilled employees from previously disadvantages groups has led to a phenomenon called 'poaching'. The well-skilled workers are often headhunted by other companies which offer them high income. This is in line with a view of Gul, Akbar and Jan (2012) who reinforce that many employers are reluctant to provide employees with capacity building in case they eventually exit the organisation. In addition, most organisations are striving to cut expenditure in this poor economic climate in South Africa and one of the areas of expenditure that tends to be cut is that of capacity building of employees. Capacity building may be seen as a luxury item in the budget of the organisation.

In accordance with the literature reviewed, the following research hypotheses were tested at the significance level of 5\%:

- H1: Capacity building has a positive relationship with EE implementation.

- H2: Provision of professional development has a positive relationship with EE implementation.

- H3: The processes within the organisation have a positive relationship with EE implementation.

- H4: The internal environment of the organisation has a positive relationship with EE implementation.

\section{Methodology}

\section{Research design}

According to Creswell (2014), there are three research processes in social sciences, namely explanatory research, exploratory research, and descriptive research. This study utilised exploratory research with a quantitative method. Quantitative research is highly pre-determined, fixed, rigid and structured to promote the reliability and validity of the data of the research project. For this study, capacity building is the independent variable whilst EE implementation is a dependent variable. Exploratory research focuses on clarifying and defining the problem of a particular nature that has not been clearly defined in a given setting. Additionally, exploratory research addresses all types of research questions and is used when problems are at an initial stage (Adams \& Lawrence, 2015). As such, an exploratory study would be suitable for this particular study as no researcher has conducted it before. Exploratory research is usually utilised to develop formal hypotheses and stands as a foundation for research projects of the future. Only exploratory research helped to develop all five hypotheses for this study. Exploratory research gives a better comprehension of a problem or concept. In respect of this study, exploratory research focuses on the insights drawn through reviewing current literature as contained in reports, books, periodicals and studies that relates to the investigation associated with capacity building and EE implementation. In addition, a survey was used in this study.

\section{Total population and sample size}

In this study, the target population comprises all employees who occupy lower and middle level positions, except those from the historically advantaged group as well as foreign nationals who do not hold line management and human resource management positions at the selected private company. The new amendment that now excludes foreign nationals as part of the designated groups is contained in the Employment Equity Amendment Act 47 of 2013, which was enacted on 01 August 2014. Therefore, this group is now excluded from the target population. Hence, the target population group was 302. For this study, the target population of 302 consisted of sub-groups (75 Indians, 150 African black people, 40 Coloureds [0 South African Chinese], 24 white women and 13 employees with disability). For this study, only one company was selected to serve as the case study from which the respondents were drawn. Because of the fact that it was impossible to cover the entire respondents in the population, determining a sample size was crucial for the study. The statistical formula utilised for calculation of sample size for this study was adopted from Wiid and Diggines (2011) and is as follows:

Formula: $n=N / 1+N(e 2)$

[Eqn 1]

Where:

$e, 0.05$, the level of precision.

$N$, the population

$n$, expected sample size

In line with the statistical formula, the sample size for the study at 5\% level of significance is $n=302 / 1+302(0.0025)=$ 172 respondents. In summary, the population was 302, the sample selected was 172 , a total of 123 responses were returned, and $n=95$ were usable responses.

\section{Sampling procedure and sample size}

Probability sampling was chosen in order to lessen the bias in the selection, as well as in order to conduct statistical inferences from the data. For the researcher to eliminate sampling bias, the stratified sampling technique and simple random sampling technique without replacement were utilised. The stratified sampling technique breaks down the population into groups or 'strata'. After obtaining the sample size, the allocation of each stratum was carried out and calculated utilising the following formula by Wushe and Shenje (2019): 
Formula: $n i=n * N i / N$

[Eqn 2]

Where:

$N$, number of members in the entire population

$N i$, number of members in the population from strata $\mathrm{i}$ for $\mathrm{i}=1,2,5$.

$n$, sample size.

$n i$, number of members in the sample from strata i for $\mathrm{i}=1,2,5$.

In accordance with the statistical formula $n i=n * N i / N$, the racial make-up of these 172 respondents was then drawn randomly without replacement from the strata, and it constituted 85 African black people, 43 Indians, 23 Coloureds, 14 white women and 7 employees with disabilities across all races. This formula was utilised to pick a reasonably sized sample that equates the aggregate representation of Indian employees, African employees, Coloured employees, women and employees with disabilities. In this case, the simple random sampling technique without replacement was utilised to pick the members from each stratum. Since random sampling without replacement does not permit the same element of the target population to be chosen in the sample more than once, it has greater efficiency as compared to a random sampling with replacement.

\section{Measuring instruments}

In this study, data were collected through a structured questionnaire to assess the influence of capacity building on EE implementation. By incorporating pre-coded questions, data capturing may be easily done as the respondent is only asked to put an $(X)$ next to the numerical code on each statement on the Likert scale. The responses of the respondents were provided on a five-point Likert scale in which 'strongly disagree' is represented by numeric (1) 'disagree' is represented by numeric (2) 'neutral' is represented by numeric (3) 'agree' is represented by numeric (4) and 'strongly agree' is represented by numeric (5) 'Disagree' and 'strongly disagree' scores are represented by scores equivalent to a mean of $0-2.5$. The score mean of 2.6-3.4 is represented by the Likert scale score equivalent to 'neutral'. The score mean of 3.5-5.0 is represented by the Likert scale score equivalent to 'strongly agree' and 'agree'. Mean calculations were conducted utilising Statistical Package for the Social Sciences (SPSS) software to analyse the respondents' responses and subsequently address the objectives of this study.

\section{Data analysis}

Gray (2017) posits that the statistical analysis is the key tool for organising, highlighting and extracting information for hypotheses testing, developing theories, as well as drawing conclusions from the existing investigation. Statistics explore the interdependence and relationships between variables, read data, determine the degree of existing relationships, deduce the sense of data and build certainties in the findings. The responses were first recorded in Excel and then exported to SPSS. The responses captured in a data set were analysed utilising the latest version of the SPSS (version 25 for Windows). The analysis of the statistics was carried out in two phases, that is, the descriptive statistical analysis and inferential statistics. The SPSS version 25 for Windows was also used to analyse the questionnaire in order to test the hypotheses statistically. The SPSS version 25 for Windows assists to break the gathered raw data into simple tabular forms of a quantitative nature that make for easy assimilation and understanding.

\section{Ethical considerations}

The ethical clearance for this research was granted by the university. As part of ethical consideration, permission to conduct research at the selected company in the financial sector was obtained. Furthermore, a letter of permission to carry out the research was attached to every questionnaire that was sent to the respondents. During the research study, the following issues were considered: violation of privacy, informed consent, confidentiality and anonymity, rectification of any harm, information concealment, debriefing and deception of respondents. The questionnaires that were completed by respondents were kept in a safe place and will only be shredded after a 5 year period.

\section{Results}

The questionnaire containing 42 Likert scale typed statements was distributed to a sample of 172 selected respondent employees from the selected organisation. The response rate was approximately $72 \%$, as 123 respondents returned the questionnaire. In the scrutiny exercise of the 123 returned questionnaires, it was found that 28 questionnaires were incomplete and therefore were discarded for any further analysis. Therefore, the researcher considered 95 questionnaires for the analysis of the data.

The Cronbach Alpha was utilised as a measurement item for internal consistencies and construct stability with regard to capacity building and EE implementation. Reliability is computed by taking several measurements on the same subjects. Reliability entails the measurement instrument that produces the same outcome from the same inputs (Bryman \& Bell 2015). A reliability coefficient of 0.60 or higher is considered as 'acceptable' for a newly developed construct. The reliability scores for all sections exceeded the recommended Cronbach's Alpha value. As seen in Table 2, professional development and organisational process both scored 0.69, internal environment scored 0.70, unfair

TABLE 2: Reliability test.

\begin{tabular}{lcc}
\hline Sub-variable & Number of items & Cronbach's alpha \\
\hline Capacity building & 5 & \\
Professional development & 5 & 0.69 \\
Organisational processes & 4 & 0.69 \\
Internal environment & & 0.70 \\
Employment equity & 5 & 0.76 \\
Unfair discrimination & 5 & 0.76 \\
Affirmative action & &
\end{tabular}

Source: Utete, R. (2020). The influence of capacity building on employment equity implementation and employee performance: A case study of a private company in the financial industry. Doctorate, Dissertation, Durban: Durban University of Technology 
discrimination garnered 0.76 and affirmative action scored 0.76 .

As can be seen from Table 3, there was an even spread of females and males in this study. Females comprised 50.5\%, whilst $49.5 \%$ were males. In this study, $77.90 \%$ of the staff are up to the age of 35 years. In this study, $87.4 \%$ of the participating employees do not have more than 9 years of experience. In terms of race, the organisation in this study has more Africans, followed by Indians, then Coloureds and the least were white women. Upon examining the educational qualifications, the study found that the majority of respondents $(74.70 \%)$ possessed diploma and degree qualifications.

\section{Descriptive analysis}

In this study, capacity building is assessed within three areas, namely professional development, organisational processes, and internal environment. The responses of the respondents were provided on a five-point Likert scale in which 'strongly degree' is represented by numeric (1) 'disagree' is represented by numeric (2) 'neutral' is represented by numeric (3) 'agree' is represented by numeric (4) and 'strongly agree' is represented by numeric (5) 'Disagree' and 'strongly disagree' scores are represented by scores equivalent to a mean of 0-2.5. The score mean of 2.6-3.4 is represented by the Likert

\begin{tabular}{|c|c|c|c|c|}
\hline Demographic variable & Category & $\begin{array}{l}\text { Valid percent } \\
\text { responses }\end{array}$ & $\begin{array}{l}\text { Absolute } \\
\text { responses }\end{array}$ & Total \\
\hline \multirow[t]{2}{*}{ Gender of respondents } & Male & 50.50 & 95 & 95 \\
\hline & Female & 49.50 & & \\
\hline \multirow{7}{*}{$\begin{array}{l}\text { Age of respondents } \\
\text { (in years) }\end{array}$} & $21-25$ & 13.70 & 95 & 95 \\
\hline & $26-30$ & 31.60 & & \\
\hline & $31-35$ & 32.60 & & \\
\hline & $36-40$ & 12.60 & & \\
\hline & $41-45$ & 0.00 & & \\
\hline & $46-50$ & 5.30 & & \\
\hline & $>50$ & 4.20 & & \\
\hline \multirow{6}{*}{$\begin{array}{l}\text { Length of service of } \\
\text { respondents (in years) }\end{array}$} & $0-4$ & 31.60 & 95 & 95 \\
\hline & $5-9$ & 55.80 & & \\
\hline & $10-14$ & 10.50 & & \\
\hline & $15-19$ & 1.10 & & \\
\hline & $20-24$ & 0.00 & & \\
\hline & $25+$ & 1.10 & & \\
\hline \multirow[t]{8}{*}{ Race of respondents } & $\begin{array}{l}\text { African black } \\
\text { people }\end{array}$ & 40.00 & 95 & 95 \\
\hline & $\begin{array}{l}\text { African black people } \\
\text { with disability }\end{array}$ & 1.10 & & \\
\hline & White woman & 5.30 & & \\
\hline & $\begin{array}{l}\text { White women with } \\
\text { disability }\end{array}$ & 2.10 & & \\
\hline & Indian & 32.60 & & \\
\hline & $\begin{array}{l}\text { Indian people with } \\
\text { disability }\end{array}$ & 2.10 & & \\
\hline & Coloured & 16.80 & & \\
\hline & $\begin{array}{l}\text { Coloured people } \\
\text { with disability }\end{array}$ & 0.00 & & \\
\hline \multirow{4}{*}{$\begin{array}{l}\text { Qualifications of } \\
\text { respondents }\end{array}$} & Diploma & 50.50 & 95 & 95 \\
\hline & Degree & 24.20 & & \\
\hline & Post-graduate & 5.30 & & \\
\hline & Matric & 3.20 & & \\
\hline
\end{tabular}

Source: Utete, R. (2020). The influence of capacity building on employment equity implementation and employee performance: A case study of a private company in the financial industry. Doctorate, Dissertation, Durban: Durban University of Technology scale score equivalent to 'neutral'. The score mean of 3.5-5.0 is represented by the Likert scale score equivalent to 'strongly agree' and 'agree'. Mean calculations were conducted utilising SPSS software to analyse the respondents' responses and subsequently address the objectives of this study.

The results in Table 4 clearly point to a significant number of respondents seeing themselves as lacking the appropriate experience to hold higher positions within the organisation, with a mean score of 1.86. A sign of frustration may be detected in respect of the staff, given that the designated employees pointed out that they cannot see themselves occupying a higher position because of them having inadequate experience. Hideg and Ferris (2014) indicate that employees from designated groups need much greater exposure to workrelated aspects. This correlates with the view held by the respondents that if they were given the necessary work experience, they may get to a higher level, as indicated by a mean score of 3.67. This means that, from a practical organisational point of view, the respondents do not believe that the experience they possessed could see them as being in a position to undertake higher levels of work. The results in Table 4 also show that the respondents felt that if they received appropriate training and development, they may qualify for a higher position in their organisation, with a mean score of 3.98 . Some concerns could also be seen in relation to that the respondents did not feel that their organisation gave them appropriate skills to handle decision-making in circumstances where uncertain conditions may arise.

In respect of organisational processes, the promotion of $\mathrm{EE}$ is dependent, amongst other things, on having well-defined development processes for individual mobility within the organisation, as well as a clearly formulated promotions policy. In this respect, the respondents agreed that a well-formulated policy on promotions and training supports the elevation of employees from designated groups, as shown by a mean score of 3.78. A well-defined development process

TABLE 4: Descriptive analysis $(n=95)$.

\begin{tabular}{|c|c|c|c|c|}
\hline Statement & $N$ & Maximum & Mean & $\begin{array}{l}\text { Standard } \\
\text { deviation }\end{array}$ \\
\hline $\begin{array}{l}\text { I can see myself holding a higher } \\
\text { position in the organisation because I } \\
\text { have the required experience }\end{array}$ & 95 & 5 & 1.83 & 1.586 \\
\hline $\begin{array}{l}\text { If I got the appropriate training and } \\
\text { development, I may qualify for a higher } \\
\text { position at my organisation }\end{array}$ & 95 & 5 & 3.98 & 0.956 \\
\hline $\begin{array}{l}\text { If I was given the necessary work } \\
\text { experience, I may get a higher position } \\
\text { at my organisation }\end{array}$ & 95 & 5 & 3.86 & 0.847 \\
\hline $\begin{array}{l}\text { The pleasant work environment } \\
\text { supports the elevation of employees } \\
\text { from designated groups }\end{array}$ & 95 & 5 & 3.68 & 0.780 \\
\hline $\begin{array}{l}\text { A well-formulated policy on promotions } \\
\text { and training supports the elevation of } \\
\text { employees from designated groups }\end{array}$ & 95 & 5 & 3.78 & 0.844 \\
\hline $\begin{array}{l}\text { A supportive culture is important for } \\
\text { employment equity implementation }\end{array}$ & 95 & 5 & 3.86 & .813 \\
\hline $\begin{array}{l}\text { I have been given the appropriate skills } \\
\text { by the organisation to make the correct } \\
\text { decisions when there have been } \\
\text { uncertain conditions }\end{array}$ & 95 & 5 & 3.97 & 0.769 \\
\hline Valid $N$ (listwise) & 95 & - & - & - \\
\hline
\end{tabular}

Source: Utete, R. (2020). The influence of capacity building on employment equity implementation and employee performance: A case study of a private company in the financial industry. Doctorate, Dissertation, Durban: Durban University of Technology 
for an individual to move from one job to another is crucial in order to effectively implement EE. In terms of the internal environment, majority of respondents show that a supportive culture is important for EE implementation, as pointed out by a mean score of 3.67. The majority of respondents (mean score of 3.68) were of the view that a pleasant work environment supports the elevation of employees from designated groups. As a way of accommodating employees with disabilities, it is useful to make sure that buildings are accessible, Braille is made available for visually impaired employees and hearing impaired employees are given sign language interpreters at conferences, workshops and meetings.

In respect of organisational processes, there is incongruency between the process of promotions and that of the development of designated employees, as indicated by the polarities between promotion and professional development. The polarities tend to reveal an element or existence of 'unfairness'. In this respect, one would not lose sight to the historical context that South Africa finds itself in, that there has been a hierarchy of EE beneficiaries that arose which favoured certain races within the designated groups to benefit a lot more in respect of training and promotion, as compared to treating all the different racial groups who are designated equally. However, this practice by companies has been dissipating over a period of time.

\section{Regression analysis}

Inferential statistics were used in this study to test hypotheses and predictions. For parametric tests, the main tests conducted were multiple regression analysis and analysis of variance
(ANOVA). Multiple linear regression analysis was undertaken to determine whether the independent variable (capacity building; professional development; organisational processes; and internal environment) influences the dependent variable (EE). Multiple linear regression analysis was also utilised in determining which amongst the independent subvariables (professional development, organisational processes, and internal environment) has a higher contribution to the variation of the dependent variable (EE). Table 5 illustrate and cover the results relating to capacity building and EE.

The $R$-square value shown in the 'model summary' assists to explain the variance in the dependent variable (EE). In Table 5 , the value of $R$-square is 0.808 . This points to the independent variable (capacity building; professional development; organisational processes; and internal environment) as a predictor (influencing) of the dependent variable (EE) by $80.8 \%$. This also means that there are other independent variables which were not considered in this study, but are crucial in explaining EE.

The results of this study revealed that capacity building is a major contributor to the achievement of EE as indicated by $R$-square, which is 0.808 (Table 5). This implies that capacity building explained $80.80 \%$ of the total variance. One can conclude that rigorous investment in capacity building is enough to realise great strides in EE implementation, especially at under-represented levels. For testing the statistical significance of the regression model, the ANOVA technique was used. Analysis of variance tests whether the regression model is a perfect descriptor of the

TABLE 5a: Regression analysis $(n=95)$

\begin{tabular}{lcccc}
\hline Model & $\boldsymbol{R}$ & $\boldsymbol{R}$-Square & Adjusted $\boldsymbol{R}$-square & Standard error of the estimate \\
\hline 1 & $0.429 \mathrm{a}$ & 0.808 & 0.37 & 0.21211 \\
\hline
\end{tabular}

a. Predictors (Influencers): (Constant), Capacity building (professional development, organisational processes and internal environment).

b. Dependent variable: Employment equity.

TABLE 5b: Analysis of variance (ANOVA).

\begin{tabular}{|c|c|c|c|c|c|}
\hline Model & Sum of Squares & $D f$ & Mean Square & $F$ & Significance \\
\hline 1. Regression & 8.080 & 4 & 1.620 & 20.108 & $0.000 \mathrm{~b}$ \\
\hline 2. Residual & 21.002 & 256 & 0.281 & - & - \\
\hline Total & 29.082 & 260 & - & - & - \\
\hline
\end{tabular}

Significant at the 0.01 level.

TABLE 5c: The coefficients and ranking of standardised coefficients.

\begin{tabular}{|c|c|c|c|c|c|}
\hline \multirow[t]{2}{*}{ Model } & \multirow{2}{*}{$\begin{array}{c}\text { Unstandardised coefficient } \\
\text { B }\end{array}$} & \multicolumn{4}{|c|}{ Standardised coefficient } \\
\hline & & Std. error & $\beta$ & $t$ & Sig. \\
\hline 1 (Constant) & 6.125 & 371 & - & 17.865 & 0.000 \\
\hline Professional development & -0.458 & 0.243 & 0.594 & 10.372 & 0.000 \\
\hline Organisational processes & -0.232 & 0.236 & 0.549 & 5.989 & 0.000 \\
\hline Internal environment & 0.244 & 0.247 & 0.259 & 4.628 & 0.000 \\
\hline
\end{tabular}

Dependent variable: Employment equity.

TABLE 5d: Ranking of standardised coefficient, beta $(\beta)$.

\begin{tabular}{lcccc}
\hline Independent variables & Standardised coefficient beta & Rank & - & - \\
\hline Professional development & 0.594 & 1 & - & - \\
Organisational processes & 0.549 & 2 & - & - \\
Internal environment & 0.259 & 3 & - & - \\
\hline
\end{tabular}

Source: Utete, R. (2020). The influence of capacity building on employment equity implementation and employee performance: A case study of a private company in the financial industry. Doctorate, Dissertation, Durban: Durban University of Technology 
relationship between predictor variables (capacity building; professional development; organisational processes and internal environment) and dependent variables (EE). Hence, in considering the results in Table 5, the model is a perfect descriptor of the connection between independent variables (capacity building: professional development; organisational processes and internal environment) and the dependent variable (EE) $(F=20.108 ; p=0.000)$. A high $F$-value reflects a good descriptor value, whilst a small $p$-value means that the results are significant and hence become sufficient for predicting the response. The F-value is utilised to conclude whether the entire model has statistically significant predictive capability. The $p$-value is considered statistically significant when it is less than or equal to 0.05 . Therefore, this indicates that the independent variables (capacity building; professional development; organisational processes and internal environment) are significant in explaining the variation in the dependent variable (EE). Thus, one can conclude that there is a positive relationship between capacity building and EE implementation. With the ability to learn within a realistic time to carry out a job, relevant experience and or prior learning are factors that are considered for the suitability of a person.

Table 5 contains the coefficients that allow one to make a comparison as to which of the three independent sub-variables (professional development, organisational processes and internal environment) makes the highest contribution to the variation of $\mathrm{EE}$ (dependent variable). Hence, the Beta standardised coefficients were utilised in making comparisons. The results indicate that professional development is the most predictor (influencing) variable that contributes the highest to the variation of $\mathrm{EE}(\beta=0.594$; $p=0.000)$. Following were organisational processes: $(\beta=0.549$; $p=0.000)$ and the internal environment $(\beta=0.259 ; p=0.000)$. This implies that skills are critical for managerial level and their presence makes the implementation of EE that much easier. From the findings of this study, it is clear that successful EE implementation without negatively affecting performance of the business is largely achieved when prospective equity appointees are provided with sound professional development. This implies that skills are critical and their presence makes the implementation of EE that much easier.

Again in respect of hypothesis testing, it emerged that there is a positive relationship between capacity building and EE implementation. The results report that Pearson's Chi-Square $p<0.001$ is below the cut-off parameter: Pearson's significance $(p<0.05)$. This test shows that organisations should give capacity building priority in order to accomplish meaningful EE implementation. Therefore, the hypothesis (H1) was accepted. This test shows that organisations should give capacity building priority in order to accomplish meaningful EE implementation. The results of this study contribute to the advancement of $\mathrm{EE}$ as it empirically reveals that employing intensive capacity building is a major EE implementation success factor. The Pearson's Chi-Square showed that professional development has a positive relationship with EE implementation. The Pearson's Chi-Square test result of $p<0.01$ is beneath the cut-off parameter that is Pearson's significance $(p<0.05)$. Hence, the results of the statistical tests reveal a significant relationship between professional development and the elimination of discrimination at the workplace. Therefore, the hypothesis (H2) was accepted. Employees from designated groups require professional development to commensurate with the new skills and knowledge expected in higher positions.

It should be noted that there is a positive relationship between sound organisational processes and EE implementation. The results report that Pearson's Chi-Square $p<0.001$ is below the cut-off parameter: Pearson's significance $(p<0.05)$. Consequently, the hypothesis (H3) was accepted. Management is required to verify the capacity of the business organisation with regard to designing an EE policy that reflects a commitment to the fairness and equity in the workplace. Organisational processes and policies such as the provision of reasonable accommodation in the form of flexible working hours and the prohibition of sexual harassment are important in addressing past discriminatory tendencies.

The positive relationship between the state of the internal environment and EE was revealed by Pearson's Chi-Square test result of $p<0.03$ which is under the cut-off parameter: Pearson's significance $(p<0.05)$. Hence, hypothesis $(\mathrm{H} 4)$ was accepted. Employment equity gathers momentum in an organisation when previous cultures, core values and basic structure are dismantled to form new paradigms that enhance EE implementation.

\section{Discussion of the findings}

A sign of frustration may be detected in respect of the staff, given that the designated employees pointed out that they cannot see themselves occupying a higher position because of them having inadequate experience. The finding is in line with a study carried out by Cilliers and Stone (2005) which focused on EE practices in three information technology companies in South Africa involving a survey of 285 participants where the results revealed a lack of managerial and leadership skills amongst designated groups. Some concerns could also be seen as the respondents did not feel that their organisation gave them appropriate skills to handle decision-making in circumstances where uncertain conditions may arise. In relation to the financial sector, designated employees who want to occupy managerial positions should gain skills that are crucial for the financial sector, such as customer care skills, communication skills, time management skills, presentation skills and conflict management skills, amongst others.

The results of this study revealed that capacity building is a major contributor to the achievement of EE. There is a positive relationship between capacity building and EE implementation. According to Ojokuku and Adegbite (2014), formal programmes of capacity building prepare employees 
to be ready to take on higher posts. According to Yülek (2018), capacity building may help the organisation to effectively deal with disequilibria in the labour market. In this case, the disequilibrium is addressed by reviewing the human resource development policies and embarking on the reallocation of organisational resources as part of dealing with the internal environment. Human capital leadership has a role to play in encouraging a change of organisational culture. Amongst three independent sub-variables (professional development, organisational processes and internal environment), professional development makes the highest contribution to the variation of EE (dependent variable). The results indicate that professional development is the most predictor (influencing) variable that contributes the highest to the variation of EE. According to Jenna (2015), organisations that continuously capacitate their employees with skills and resources always have willing and ready employees from designated groups to succeed in up to $61 \%$ of positions that may arise within the organisation. This finding is in line with Onwujekwe et al. (2020) who studied capacity building in health sector in Nigeria and found that workshops provided employees with new skills and competencies.

There is a positive relationship between the state of the internal environment and EE. Capacity building plays a fundamental role in transforming the culture within the organisation that is associated with unfair discrimination, segregation and stereotypes (Maiyo \& Yamoah 2013). A study carried out by Potgieter et al. (2017) on career advancement challenges faced by people with disabilities at work in the South Africa found out that generally people with disabilities encounter career advancement challenges. They found that human resource practices particularly those that aligned to promotion opportunities discriminate against employees with disabilities. Professional development has a positive relationship with EE implementation. Fierce competition amongst businesses, particularly in the financial sector, requires properly qualified and skilled employees for these businesses to survive (Powell, Reddy, \& Juan 2016). There is a positive relationship between sound organisational processes and EE implementation. However, Goddy (2014) states that for stimulating the self-management and selfdevelopment of potential employees to occupy positions of manager, proper strategic planning is required. In the same manner, organisational systems and procedures need to be fine-tuned to meet conditions of personal growth.

\section{Practical implications}

The results inform human resources managers of the organisation under the study to put more emphasis on capacity building as the study empirically reveals that employing intensive capacity building is a major EE implementation success factor. The study also informs the organisation under this study to cultivate an environment that makes it conducive for designated groups to learn. Employment equity beneficiaries lack experience to assume duties of senior positions. Hence, managers at this organisation may consider mentorship to be availed to these employees from designated groups in order for them to gain knowledge of the job. The study results also inform the human resource management team to monitor the rate of promotions through promotional policy and skills development of employees from disadvantaged groups through training policy at the professional level, senior management level and top management levels to combat skills discrepancies. The results also inform managers of the organisation under this study that having a conducive organisational culture is imperative in promoting the implementation of EE. In light of the empirical findings and the present economic situation in South Africa, the study informs the organisations with the same or similar settings with the organisation under the study, which need to embark on EE practices, to have adequate support of sound professional development interventions because mere implementation without development of skills compromises performance improvement. At a broad level, it also informs the national, provincial and local governments about the importance of capacity building in accelerating the implementation of EE.

\section{Recommendations and limitations}

Employment equity beneficiaries lack experience to assume duties of senior positions, therefore the management of the organisation under this study should avail mentorship to these employees from designated groups in order for them to gain knowledge of the job. Awareness about the availability of professional development programmes such as mentoring and coaching should be created within the organisation. The management of the organisation under this study should provide employees from designated groups with opportunities for experiential learning. The level of competence of EE-appointees and the criticality of the job should be considered when making appointments. The organisation must foster mutual adaptation.

This research study area has limited prior research studies that have been conducted. However, the available prior research studies help to create a platform from which the research problem is better understood and also lays a concrete foundation for the literature review. In addition, some respondents did not return the questionnaires upon completion and some questionnaire were spoiled and were thus excluded from the study. This study is in short of prior research studies on capacity building and EE implementation. It is clear that embarking on capacity building is costly and the organisations may have budgetary constraints, however it is beneficial in the long run. Because this study focused on one selected company in the financial industry, future studies should focus on other industries. The future studies should research other interventions other than capacity building that might contribute towards speeding up the implementation of EE.

\section{Conclusion}

The findings of this study revealed that capacity building has great influence on the effective and proper implementation of EE. All capacity building variables namely professional development, sound organisational processes and conducive 
internal environment have positive relationships with EE implementation. The overall viewpoint is that organisations need to take capacity building seriously in order to abide by the EE requirements, there is no choice with regard to when, what and how it should be executed.

\section{Acknowledgements}

My sincerest appreciation is extended to the Human Resources Management Head of Department, Dr M.E. Lourens, for her support, encouragement and motivation. Sincere appreciation to Mrs Mercillene Mathews (Language Editor) for language editing.

\section{Competing interests}

The author has declared that no competing interest exists.

\section{Author's contributions}

I declare that I am the sole author of this research article.

\section{Funding information}

This research received funding from the Durban University of Technology.

\section{Data availability}

Data sharing is not applicable to this article as no new data were created or analysed in this study.

\section{Disclaimer}

The views and opinions expressed in this article are those of the author and do not necessarily reflect the official policy or position of any affiliated agency of the author, and the Publisher/s.

\section{References}

Adams, K.A., \& Lawrence, E.A. (2015). Research methods, statistics and applications. Thousand Oaks, CA: Sage.

Ahmad, T., Farrukh, F., \& Nazir, S. (2015). Capacity building boost employees performance. Industrial and Commercial Training, 42(3), 61-66. https://doi. org/10.1108/ICT-05-2014-0036

Bryman, A., \& Bell, E. (2015). Business research methods. Oxford: Oxford University Press.

Canham, H. (2012). Examining barriers to employment equity: The complexities of gender and race solidarities in a bank's empowerment discourses. International Journal of Psychology, 47(1), 660-660.

Cilliers, F., \& Stone, K. (2005). Employment equity practices in three South African information technology organisations: A systems psychodynamic perspective. South African Journal of Industrial Psychology, 31(2), 49-57. https://doi.org/10.4102/sajip. v31i2.193

Commission for Employment Equity (CEE). (2017). 17th Annual report (2016-2017). Retrieved from https://www.workinfo.com/index.php/articles/item/1804commission-for-employment-equity-annual-report-2016-2017/

Creswell, J.W. (2014). Research design: Qualitative, quantitative and mixed methods approaches. Thousand Oaks, CA: Sage.

Department of Economic Development and Tourism. (2014). Financial services secto assessment report 2014. Retrieved from http://www.westerncape.gov.za

El-Mouallem, L., \& Analoui, F. (2014). The need for capacity building in human resource management related issues: A case study from the Middle East (Lebanon). European Scientific Journal, 1(1), 245-254.
Farah, S., \& Waqar, A. (2015). Evaluation the role of HR audit in organization effectiveness: Evidence from banking sector in Karachi-Pakistan. Evaluation, 7(22), 149-161.

Felício, J.A., Couto, E., \& Caiado, J. (2014). Human capital, social capital and organizational performance. Management Decision, 52(2), 350-364. https://doi. org/10.1108/MD-04-2013-0260

Goddy, O.I. (2014). Capacity building - A tool for increase productivity in Nigeria public sector organization. Global Journal of Human Resource Management, 2(3), 45-58.

Gray, E.D. (2017). Doing research real world. Thousand Oaks, CA: Sage.

Gul, A., Akbar, S., \& Jan, Z. (2012). Role of capacity development, employee empowerment and promotion on employee retention in the banking sector of Pakistan International Journal of Academic Research in Business and Social Sciences, 2(9), 284.

Heerden, A.V. (2015). Consequences of late/ non-filing of employment equity reports. South African Labour Guide: Pretoria.

Hideg, I., \& Ferris, D.L. (2014). Support for employment equity policies: A selfenhancement approach. Organizational Behavior and Human Decision Processes, 123(1), 49-64. https://doi.org/10.1016/j.obhdp.2013.11.002

Horwitz, F.M., \& Jain, H. (2011). An assessment of employment equity and broad based black economic empowerment developments in South Africa. Equality, Diversity and Inclusion: An International Journal, 30(4), 297-317. https://doi. org/10.1108/02610151111135750

Jain, H.C., Horwitz, F., \& Wilkin, C.L. (2012). Employment equity in Canada and South Africa: A comparative review. The International Journal of Human Resource Management, 23(1), 1-17. https://doi.org/10.1080/09585192.2011.606115

Jenna, P. (2015). The importance of performance management. Retrieved from http:// technologyadvice.com/blog/human-resources/importance-of-performancemanagement/

Li, M., Mobley, W.H., \& Kelly A. (2013). When do global leaders learn best to develop $\mathrm{CI}$ ? An investigation of the moderating role of experiential learning style. Journal of Academy of Management Learning and Education, 12(1), 32-50.

Maiyo, P., \& Yamoah, E.E. (2013). Capacity building and employee performance. Journal of Canadian Social Science, 9(3), 42-45.

Matyala, Q. (2016). Call for employment equity tribunals to ensure redress. Cape Times. 2016 Apr 25. p. 1.

Mkhonza, T. (2017). 50 JSE securities companies not compliant with EE Act. Business Report. 2017 Oct 31. p. 1.

Ojokuku, R., \& Adegbite, T. (2014). The impact of capacity building and manpower development on staff performance in selected organisations in Nigeria. International Journal of Economics, Commerce and Management, 2(5), 1-9.

Olckers, C., \& Zyl, L.V. (2016). The relationship between employment equity perceptions and psychological ownership in a South African Mining House: The
role of ethnicity. Journal of Social Indicators Research, 127(2), 887-901. https:// role of ethnicity. Journal of Social Indicc
doi.org/10.1007/s11205-015-0972-z

Onwujekwe, O., Mbachu, C., Etiaba, E., Ezumah, N., Ezenwaka, U., Arize, I., Okeke, C. ... Uzochukwu, B. (2020). Impact of capacity building interventions on individual and organizational competency for HPSR in endemic disease control in Nigeria: A qualitative study. Implementation Science, 1(1), 1-13. https://doi.org/10.1186/ qualitative study. Im
s13012-020-00987-z

Portnoi, L. (2003). Implications of the Employment Equity Act for the higher education sector: Perspectives on higher education. South African Journal of Higher Education, 17(2), 79-85.

Potgieter, I.L., Coetzee, M., \& Ximba, T. (2017). Exploring career advancement challenges people with disabilities are facing in the South African work context. SA Journal of Human Resource Management, 15(1), 1-11. https://doi.org/10.4102/ sajhrm.v15i0.815

Powell, M., Reddy, V., \& Juan, A. (2016). Skills in South Africa: The journey towards credible planning. Journal of Development Southern Africa, 33(3), 298-311. https://doi.org/10.1080/0376835X.2016.1153456

Sesant, S. (2017). Affirmative action isn't going anywhere, says minister. Cape Argus. 2017 May 10. p. 1.

Shams, S.M.R. (2016). Capacity building for sustained competitive advantage: A conceptual framework. Journal of Marketing Intelligence and Planning, 34(5), 671-691. https://doi.org/10.1108/MIP-08-2015-0161

Statistics South Africa. (2017). Quarterly employment statistics. Work and labour Force. 28 Sept 2017. p. 1.

Utete, R. (2020). The influence of capacity building on employment equity implementation and employee performance: A case study of a private company in the financial industry. Doctorate, Dissertation, Durban: Durban University of the financial

Wiid, J., \& Diggines, C. (2011). Marketing research. Cape Town: Juta and Company Ltd.

Wushe, T., \& Shenje, J. (2019). The relationship between social media usage in the workplace and employee productivity in the public sector: Case study of government departments in Harare. South African Journal of Human Resource Management/SA Tydskrif vir Menslikehulpbronbestuur, 17(0), 1-10. https://doi. org/10.4102/sajhrm.v17i0.1116

Yeo, R.K., \& Marquardt, M.J. (2015). Interpreting action, learning and experience: Integrating action learning and experiential learning for HRD. Quarterly Journal of Human Resource Development, 26(1), 81-107. https://doi.org/10.1002/hrdq.21199

Yülek, M.A. (2018). Industrialization as capacity building: Skills, technical progress, and technical capabilities: In how nations succeed: Manufacturing, trade, industrial policy, and economic development. London: Palgrave Macmillan. 